\title{
The role of vesicoureteric reflux in the 21st century
}

\author{
Rodrigo L.P. Romao, MD \\ Division of Pediatric Urology, Division of Pediatric Surgery IWK Health Centre, Dalhousie University, Halifax, NS, Canada
}

Cite as: Can Urol Assoc J 2017;11 (1-2Suppl 1):S19. htrp://dx.doi.org/10.5489/cuaj.4349

See related article on page S13.

$\mathrm{T}$ he authors provide an in-depth, up-to-date summary of treatment strategies for vesicoureteric reflux (VUR). Nonetheless, when it comes to VUR, the main challenge encountered by pediatric urologists in the $21^{\text {st }}$ century is "WHO" deserves an intervention rather than "WHICH" intervention to offer. The authors correctly emphasize multiple times in the manuscript that treatment for VUR should be individualized. Unfortunately, there are not enough good-quality tools to assist clinicians in identifying the few individuals who will benefit from treatment and the vast majority that will get better with, without, or despite an intervention.

The last few decades have seen a shift in the decisionmaking process both in terms of diagnostic (Which populations should undergo investigation with a cystogram? Should followup cystograms be obtained at all?) and therapeutic interventions for VUR (Who deserves to be followed more closely? Who should be offered active treatment? Which treatment is more appropriate for a given patient?). Noticeably, a robust risk stratification approach aimed at identifying the small group of children with VUR at risk for significant complications - such as recurrent pyelonephritis, renal scarring, and dysfunction - is lacking.

Additionally, the lead role played by VUR as a standalone disease has slowly been replaced by the recognition of a more intricate relationship with broader categories of conditions, namely antenatal hydronephrosis, infant febrile UTIs, and bowel/bladder dysfunction. Hence, future management decisions will likely lean on understanding the role played by VUR as a bystander within the context of those conditions, which is not necessarily a bad thing. After all, as the passage immortalized by David Gilmour and Roger Waters from Pink Floyd in the lyrics of "Wish You Were Here" suggests, a walk-on part in a war might be preferable to a lead role in a cage.

Competing interests: The author reports no competing personal or financial interests.

This paper has been peer-reviewed.

Correspondence: Dr. Rodrigo L.P. Romao, Division of Pediatric Urology, Division of Pediatric Surgery IWK Health Centre, Dalhousie University, Halifax, NS, Canada; Rodrigo.Romao@iwk.nshealth.ca 